\title{
Studies on Effects of Pruning on Vegetative Traits in Stevia rebaudiana Bertoni (Compositae)
}

\author{
Raji Akintunde Abdullateef (Corresponding author) \\ Kulliyyah of Science, International Islamic University Malaysia (IIUM) \\ Kuantan 25200, Pahang, Malaysia \\ Tel: 601-2914-1037 E-mail: abdullateef_raji@yahoo.com \\ Mohamad Osman \\ Kulliyyah of Science, International Islamic University Malaysia (IIUM) \\ Kuantan 25200, Pahang, Malaysia \\ Tel: 609-571-6759 E-mail: mbopar2004@yahoo.com
}

Received: August 11, 2011

Accepted: September 1, 2011

Published: January 1, 2012

doi:10.5539/ijb.v4n1p146

URL: http://dx.doi.org/10.5539/ijb.v4n1p146

This research was financed by International Islamic University Malaysia (IIUM). Grant (TYPE A) EDW

A10-155-0702

\begin{abstract}
Stevia rebaudiana Bertoni, a natural sweetener plant with zero calorie content, becomes an inevitable alternative to sugar especially with the over 346 million diabetic population across the world. Stevia belongs to a genus of about 150 species of herbs and shrubs, a member of the family Compositae and native to Paraguay. Currently over 3 million Malaysian populations are diabetic and the dare need for this alternative sweetener substitute cannot be over emphasized. The plant being photoperiod sensitive has low vegetative yield under Malaysian environmental condition and the need therefore arises to improve this quality. Studies were carried out on effects of pruning on vegetative yield traits in Stevia in order to multiply leaves for higher quantity of sweetener extraction. Studied morphological characters include- (i) plant height, (ii) number of branches and (iii) number of leaves. Data were subjected to pair sample $t$ test at probability level $p<0.05$, analysis revealed that there were significant differences with plant height at $<0.032$, number of branches at $<0.012$ and number of leaves at $<0.001$. Pruning promoted high vegetative yield in Stevia.
\end{abstract}

Keywords: Stevia, Paraguay, Sweet steviol glycoside, Pruning, Vegetative yield, Zero calorie, Diabetics, Malaysia

\section{Introduction}

Stevia rebaudiana Bertoni, a natural sweetener plant with zero calorie content, becomes an inevitable alternative to sugar especially with the over 346 million diabetic population across the world. (WHO, 2011).

Stevia, also known as sweet leaf, or sugar leaf is a genus of about 150 species of herbs and shrubs (Robert, 2010), a member of the family Compositae and a native to Paraguay (Mark, 2009).

Strauss, (1995) reported that stevia is a non-caloric sweetener and that the sweet compounds pass through the digestive process of the body without chemically breaking down, hence making it a safe food substance for consumption by people who need to regulate their Blood glucose level.

From most of the previous work, Stevia has been reported to have no adverse effect on humans (Brandle and Rosa, 1992). The leaves could be eaten fresh or when dried and it could be boiled in tea to release the sweetener. It has been used for centuries by the Guarani Indians of Paraguay, where the Plant originated from, as sweeteners for mate tea (Goettemoeller and Ching, 1999). 


\subsection{Plant description}

The plant, under cultivation can reach up to $1 \mathrm{~m}$ or more in height (Shock, 1982) it possesses an extensive root system and brittle stems producing small, elliptic leaves. The leaves are sessile, oppositely arranged lanceolate to oblancoelate in shape, and serrated. The tiny white florets are perfect, borne in small corymbs of 2-6 florets. Corymbs are arranged in loose panicles. Seeds are contained in slender achenes, about $3 \mathrm{~mm}$ in length. Each achene has about 20 persistent pappus bristles.

\subsection{Cultivation}

Stevia prefers moist, sandy and loamy soil with high organic matter and adequate drainage. It tolerates a wide range of soil ph and it also prefers partial shade for good agronomic performance (Rhonda, 2004).

\subsection{Sweetener content of the leaves}

The zero-calorie sweetener which contains high percentage of stevioside than other glycosides is extracted from stevia leaves (Mark, 2009). The steviol glycosides are responsible for the sweet taste of the leaves of the stevia plant. Morita et al (2009) and Duke (1993) reported earlier that an extract of one or more of the glycosides may be up to 300 times sweeter than sugar. They are heat-stable, pH-stable, and do not ferment (Brandle, 2004).

\subsection{Photoperiod sensitivity}

Stevia is an obligate short day plant with a critical day length of about $13 \mathrm{~h}$ and therefore requires short days for flowering (Brandle et al, 2000).

\subsection{Malaysian diabetic population}

In Malaysia, the percentage of diabetic population kept on increasing steadily; it was expected to be over 3 million by 2010, with further industrialization and modernization (Ministry of Health, Malaysia, 1997).

In light of the above the dare need for an alternative sweetener substitute with low calorie for this growing diabetic population becomes inevitable. Stevia was introduced to Malaysia about ten years ago as a potential alternative natural sweetener to sugar. The plant being photoperiod sensitive has low vegetative yield under Malaysian condition and the need therefore arises to improve this trait in the crop.

\subsection{Pruning practice}

When plant apical shoots are pruned the apical buds are removed, the lateral buds in the axils of the leaves below the cut stump assume full activity and begin to grow. These active lateral buds grow into shoots and their tips have apical buds that resume apical dominance over lateral buds in positions lower on the main stem. So when plants are pruned development of new branches are facilitated (Koning, 1994).

The aim of this work therefore is to carry out studies on effects of pruning on plants of Stevia rebaudiana in order to multiply branches and leaves for higher quantity of sweetener extraction in Malaysia.

\section{Materials and Methods}

The stevia plants were raised through stem micro-cuttings. The micro-cutting propagation was carried out by cutting the young apical shoots (YAS) of matured stevia accessions towards the apex. The cuttings used for this work were turgid, matured and healthy, as wilting, immature and unhealthy cuttings may easily get decayed in the micro-cutting mist chamber.

The excised cuttings were dipped into Indole -3-buutyric acid (IBA) for one to two seconds and then allowed to stay for 15 minutes- in order to allow the auxin get absorbed into the cut stem through the xylem. These treated stem cuttings were then inserted in the micro-cutting mist chamber in order to sprout roots.

The cuttings sprouted roots within five to seven days and they were transplanted into small sized polythene bags and were made to stay under a shed for few days (five to seven days). After this, the plants were again transplanted into large sized polythene bags before being finally transferred to the field. On the field the plants were divided into six different sections namely plots one to six with each plot comprising of 10 plants. Thus there were 60 plants in all.

The plants under good agricultural practice were allowed to grow for 10 weeks on the field and data were taken and recorded on studied morphological characteristics before being subjected to complete pruning.

Sharp small sized shear was used for pruning and care was taken not to cause any damage to the pruned shoots. The technique employed during pruning was the cut-back to bud method (Dunn et al, 2002), where the cuttings were made at a distance not too close to the buds (under cutting) as the buds may die and also not too far (over cutting) to avoid presence of too big stump above the newly emerging shoots. 
Studied morphological characters include- (i) plant height, (ii) number of branches and (iii) number of leaves. Initial readings were carried out before and after pruning, while the last reading came up after ten weeks of development of new branches and leaves.

Collected data, placed in table1, were analyzed using pair sample ' $t$ ' test analysis and histograms and line graphs were plotted (figures 1 to 3 ) in order to give the results a statistical support. Pictures were also taken concurrently (figures 4 to 5 ).

\section{Results}

The results obtained from the experiment are stated on table 1 .

The average plant heights before pruning and ten weeks after pruning showed significant difference at $p<0.032$; the corresponding standard error of the mean of this parameter was read to be 3.63012. The average number of branches in plants before and pruning also revealed they differ significantly at $p<0.012$; again with this parameter the standard error of the mean was 1.38243. Pruning effects on number of leaves also showed significant difference at $\mathrm{p}<0.001$ when the average number of leaves on plants before and after pruning were statistically compared; in this case the mean standard error was28.95677.

Histograms and line graph illustrate the pictorial view of the analyzed data as shown in the figures 1 to 3 , while plates representing pictures of the plants were placed in figures 4 to 5 .

Figures 1 to 3 are graphical expressions of the data collected on the evaluated parameters (table 1). In figure1, the values collected for plant height before pruning and after pruning treatment affects were graphically compared, it would be observed that while the values for plant height before pruning were placed on the $\mathrm{x}$ axis bellow the graph, the post pruning values on same parameter were placed above. The six histogram partitions represent the six plots of the pruning experiment. The first partition showed that the average height of plants in plot number six( table1) before pruning was above 20 but less than 22 (20.5, table1), while the recorded average value for the same parameter and same plot for post pruning effect was 22.Throughout the graph the least and highest values were compared. The sixth partition represent plot number five (table1), it recorded the highest plant height average value as the difference between the least value (15.5) and the highest value (43) equals 27.5. Similarly the first partition represents plot number six (table1), the difference between the highest value $(22 \mathrm{~cm})$ and the least value $(22.5 \mathrm{~cm})$, with the plant height parameter, is $1.5 \mathrm{~cm}$; this plot had the least increment in height.

Numbers of branches before and after development of pruned plants were also compared in figure2.There were four partitions in this histogram because some recorded values were similar (table1). From this graph it would be observed that there was increment in number of branches across all the six plots. The least increment value $(2 \mathrm{~cm})$ on number of branches was recorded in each case for histogram partitions one and two, representing plots four and five respectively, while the highest increment value $(11 \mathrm{~cm})$ on same parameter was recorded in partition four representing plot 1 of the experimental design.

Figure 3 showed graphical expression of the comparison between the average values of number of leaves before and after pruning treatment. Number of leaves increases geometrically across the experimental plots, while partition one representing plot four had the least increment value with $101 \mathrm{~cm}$, the partition six representing plot 1had the highest increment value with $295 \mathrm{~cm}$.

\section{Discussions}

The parameters evaluated in this pruning experiment showed significant differences at varying levels at probability level $\mathrm{p}<0.05$. All the parameters- plant height, number of branches and number of leaves- had high influence with the effects of pruning.

The obtained values on the mean standard error for the plant height (3.63012) and number of branches (1.38243) are quite small thereby indicating that the sample mean deviation from the population mean was minimal and that the samples are good representations of the overall population. However, the mean standard error on the number of leaves was high (28.95677), this indicated a large deviation between the sample and population means and the need to increase the sample size, though the fact still remains that there is significant difference $(0.001)$ in the number of leaves before and after pruning.

The average plant height values before and ten weeks of post pruning showed significant difference at $\mathrm{p}<0.032$. This result is not on expected, the removal of the apical meristems along with the pruned apical shoot in the stevia plants connotes the removal of the dormancy induced on the lower buds of the shoots. Cells of the apical meristems in the shoot are responsible for the secretion of the hormone called auxin (Daphne and Michael,2005), this auxin is then transported by polar gravity through the part of the plants up to the root region, in this process 
the hormone imposed dormancy on all the lower buds and therefore none of the buds could develop and extend above the apical shoot so long as the meristematic cells are still active. But the condition changed as the meristematic cells responsible for the auxin secretion were removed along with the apical shoot, meaning therefore that the dormancy induced on lower shoots is also removed. The potential lower buds 'gained freedom' and assumed full activities and then grow properly to a height higher than the initial height o the pruned plants (Dörte and Ottoline 2011). The developed shoot also impose dormancy on the other buds that are located bellow it as well, thus preventing them from growing.

The average number of branches of the plants before pruning was done compared to post pruning treatment also revealed that a significant difference exists between the two at $\mathrm{p}<0.012$. This result is in line with previous findings (Koning, 1994).When plants are pruned the lower buds become active and begin to grow, in this process the number of emerging new shoots from these lower buds below the cut region could be up to two or more, these then grow out and form more branches. Thus the final number of branches was more than the initial number of branches in Stevia.

Also with the effect of pruning on number of leaves it was revealed from the result that there was a significant difference at $\mathrm{p}<0.001$ when the average value before pruning was compared to the average value for post pruning treatment. The large increment in number of leaves (82.82 to 300.00 , table 1) as a result of pruning effects is also in line with previous findings, Chandrashekara (2007), reported an increment in number of leaves due to pruning effect on trees in home gardens of Kerala, Indian. The increment in number of leaves in pruned stevia plants may not be unconnected with the observed increment in number of branches since more leaves grew on the new branches.

\section{Conclusion}

Pruning influenced high vegetative yield in Stevia rebaudiana bertoni.

\section{Acknowledgement}

We are thankful to the research management center of the International Islamic University Malaysia (IIUM) for sponsoring this research through the endowment fund, 'EDW A10-155-0702' JAZAKUMULLAHU KHAIRAH.

\section{References}

(WHO, 2011). DiabetesFact sheet N 312 August. [Online] Available: http://www.who.int/mediacentre/factsheets/fs312/en/\%20\%20\%28Retrieved-08/08/2011\%29

Brandle, J.E. \& N. Rosa. (1992). Heritability for yield, leaf-stem ratio and stevioside content estimated from a landrace cultivar of Stevia rebaudiana. Can. J. Plant Sci. http://dx.doi.org/10.4141/cjps92-159

Brandle, J. E., Starratt, A. N. \& Gijzen, M. (2000). Stevia rebaudiana Its biological, chemical and agricultural properties. Agriculture and AgriFood Canada, Southern Crop Protection and Food Research Centre, 1391 Sandford St., London, Ontario N5V 4T3. www.Ini.unipi.it/stevia/stevia/stevia0005.htm

Brandle, Jim. (2004). FAQ - Stevia, Nature's Natural Low Calorie Sweetener. Agriculture and Agri-Food Canada. [Online] Available: http://res2.agr.ca/London/faq/stevia_e.htm. (Retrieved-08/08/2011).

Chandrashekara U. M. (2007). Effects of pruning on radial growth and biomass increment of trees growing in homegardens of Kerala, India. Agroforest Syst.

Daphne J. Osborne \& Michael T. McManus. (2005). Hormones, Signals and Target Cells in Plant Development. Published 2005, Cambridge University Press. Page 158. http://dx.doi.org/10.1017/CBO9780511546228

Dörte Müller \& Ottoline Leyser. (2011). Auxin, cytokinin and the control of shoot branching. Annals of Botany Ann Bot.

Duke, J. (1993). Stevia rebaudiana. p. 422-424. In: J. Duke, CRC handbook of alternative cash crops. CRC Press, Boca Raton, FL. www.hort.purdue.edu/newcrop/.../v4-510.html - United States

Dunn, J. M., Atkinson, C. J., \& Hipps, N. A. (2002). Effects of two different canopy manipulations on leaf water use and photosynthesis as determined by gas exchange and stable isotope discrimination, East Malling, University of Cambridge. id.wikipedia.org/wiki/Pemangkasan

Goettemoeller, J. \& A. Ching. (1999). Seed germination in Stevia rebaudiana. p. 510-511. In: J. Janick (ed.), Perspectives on new crops and new uses. ASHS Press, Alexandria, VA. www.Ini.unipi.it/stevia/stevia/v4-510.htm 
Koning, Ross E. (1994). Pruning. Plant Physiology Information Website. http://plantphys.info/plants_human/pruning.shtml

Lewis, W. H. (1992). Early uses of Stevia rebaudiana (Asteraceae) leaves as a sweetener in Paraguay. Econ. Bot. 46, 336-337. http://dx.doi.org/10.1007/BF02866633

Mark Stibich. (2009). About Stevia sweetener-Is it better than sugar? http://longevity.about.com/od/lifelongnutrition/a/stevia-extract.htm

Ministry of Health, Malaysia. (1997). The Second National Health and Morbidity Survey II - Diabetes Epidemic in Malaysia was published in 1997 by the Public Health Institute, Ministry of Health, Malaysia. [Online] Available: www.diabetes.org.my/article.php?aid=63 (Retrieved-08/08/2011)

Morita, T., Morita, K., \& Koichiro, K. (2009). Variety of Stevia rebaudiana Bertoni with a high content of Rebaudioside - A plant. Publication No:US 2009/0214753 A1. United State Patent Application Publication.

Rhonda Janke. (2004). Farming a few Acres of Herbs: Stevia. Kansas State University http://www.oznet.ksu.edu

Robert C. Artkins. (2010). New Diet revolution. Healthier-Harvest 2009. http://healthier-harvest.com/news-articles/nutritional_information/stevia.htm

Shock, C. C. (1982). Experimental cultivation of Rebaudi's stevia in California. Univ. California, Davis Agron. Progr. Rep. 122. www.hort.purdue.edu/newcrop/.../v4-510.html - United States

Strauss, S. (1995). The perfect sweetener? Technol. Rev. 98:18-20. Whitaker, J. 1995. Sweet justice: FDA relents on stevia. Human Events, 51, 11.

Table 1. Showing collected data on the average values of varying morphological characters studied in this research on Stevia

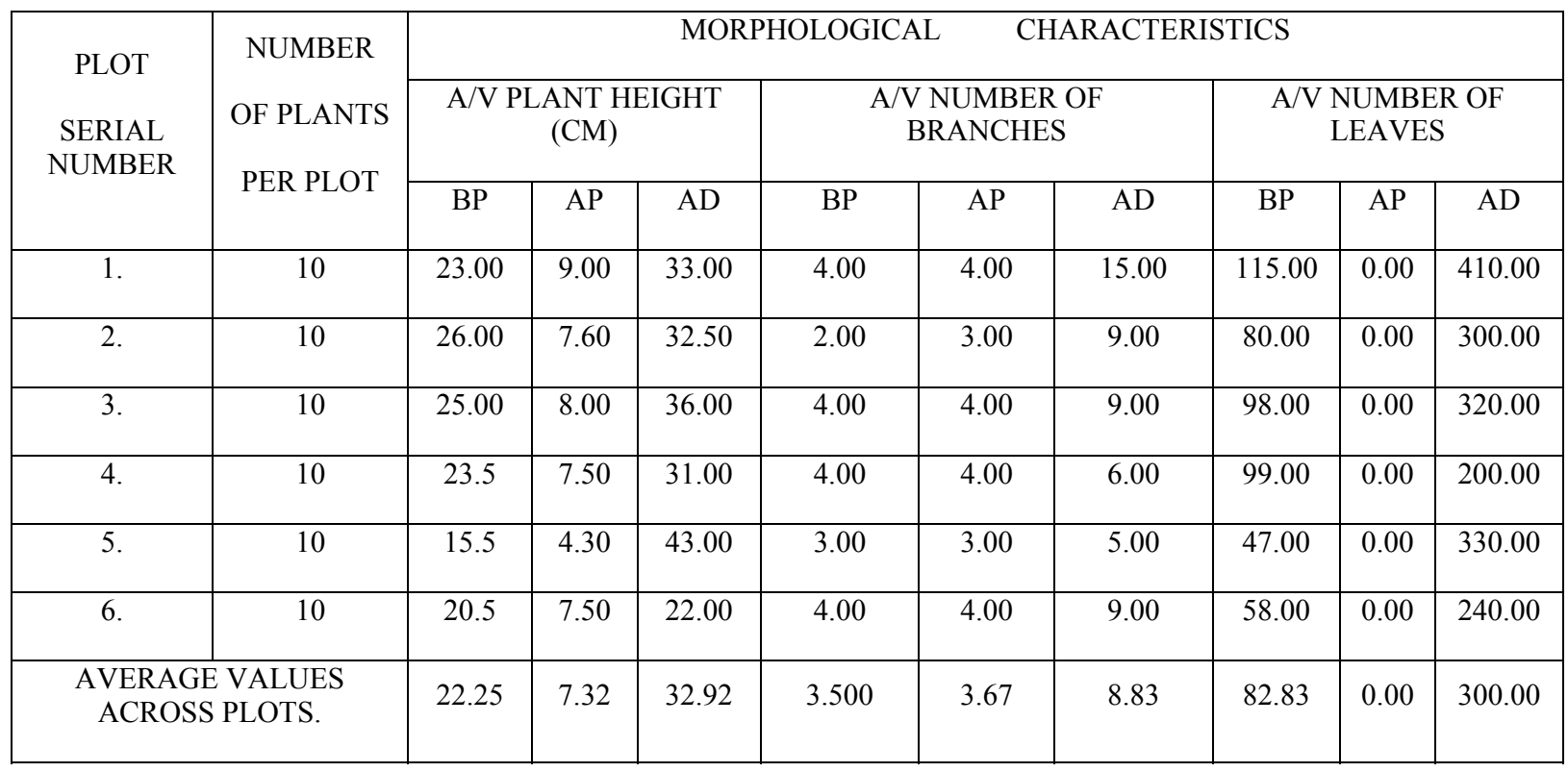

KEY- (i) BP: before pruning; (ii) AP: after pruning; (iii) AD: after development in height, branches and leaves Data in this table were subjected to pair sample t test at probability level $p<.05$; the analysis revealed that most variables were significantly different. 
Effect of Pruning on plant height in Stevia rebaudiana

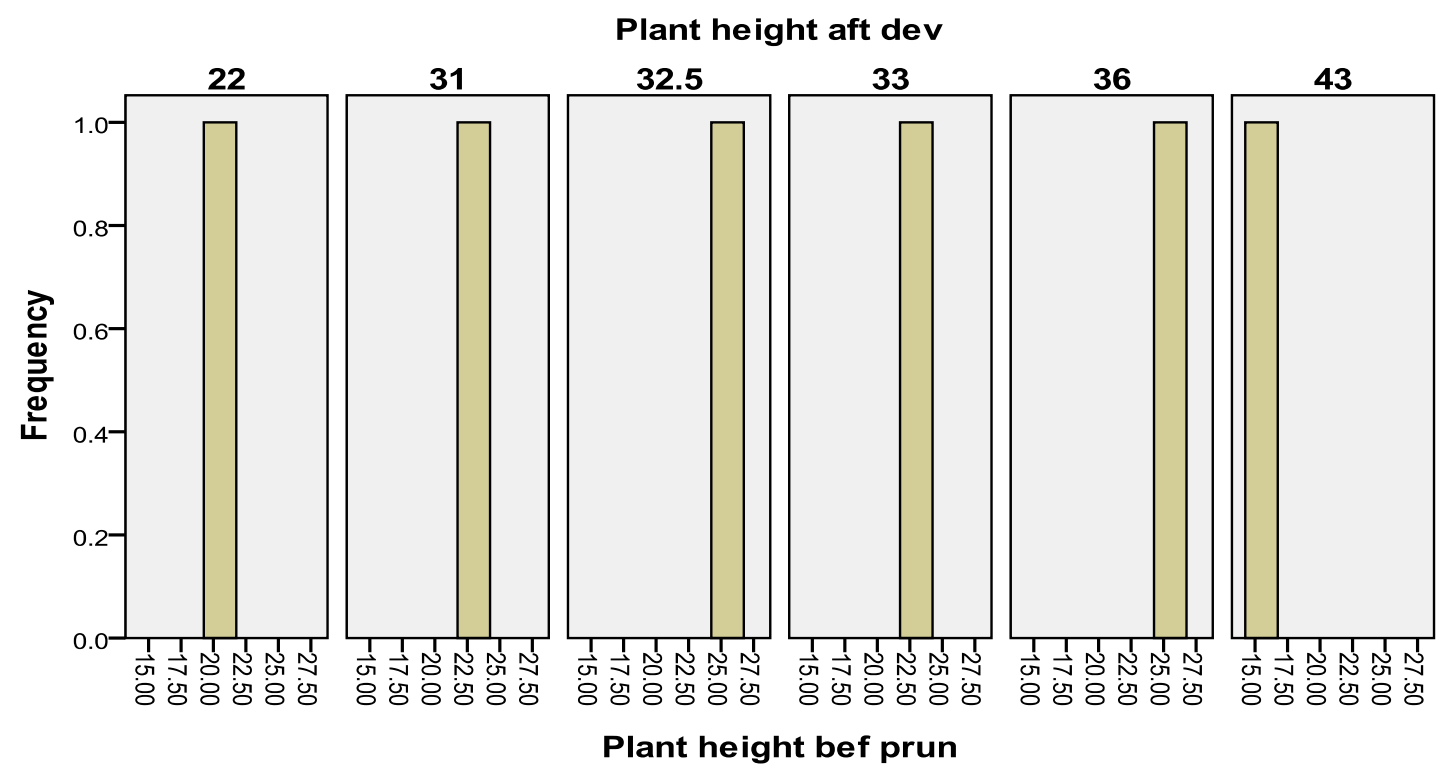

Figure 1. Graph showed Effect of pruning on plant height in Stevia rebaudiana

Effect of Pruning on Number of Branches in Stevia rebaudiana

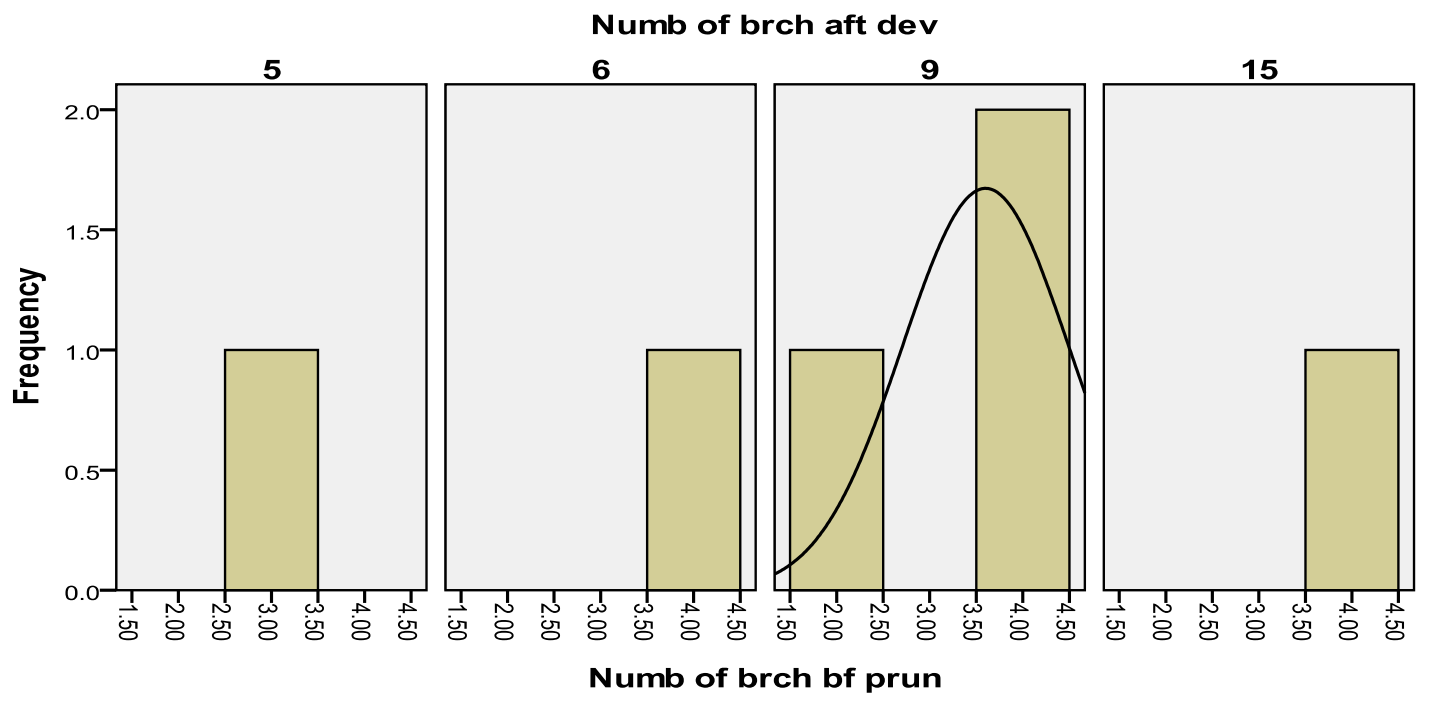

Figure 2. Graph showed Effect of pruning on number of branches in Stevia rebaudiana 
Effect of Pruning on Number of Leaves in Stevia rebaudiana

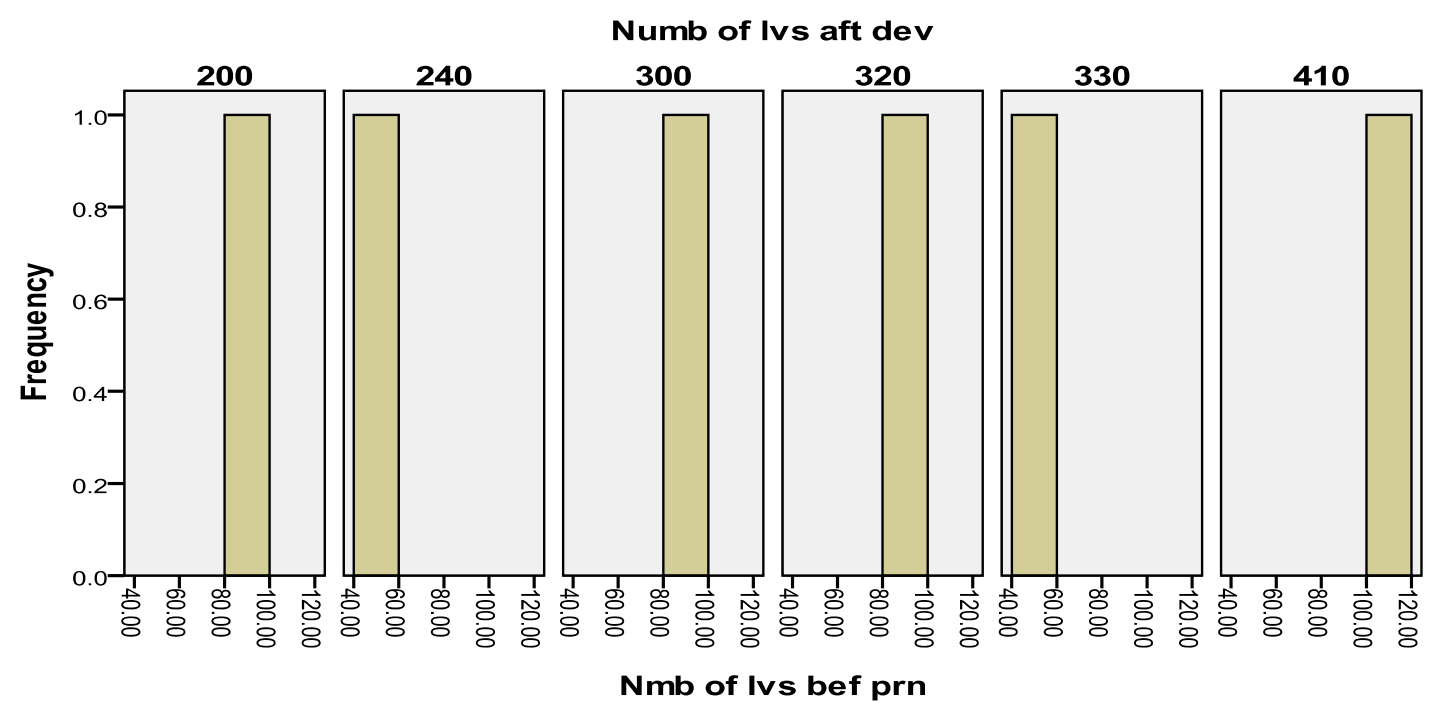

Figure 3. Graph showed Effect of pruning on number of leaves in Stevia rebaudiana

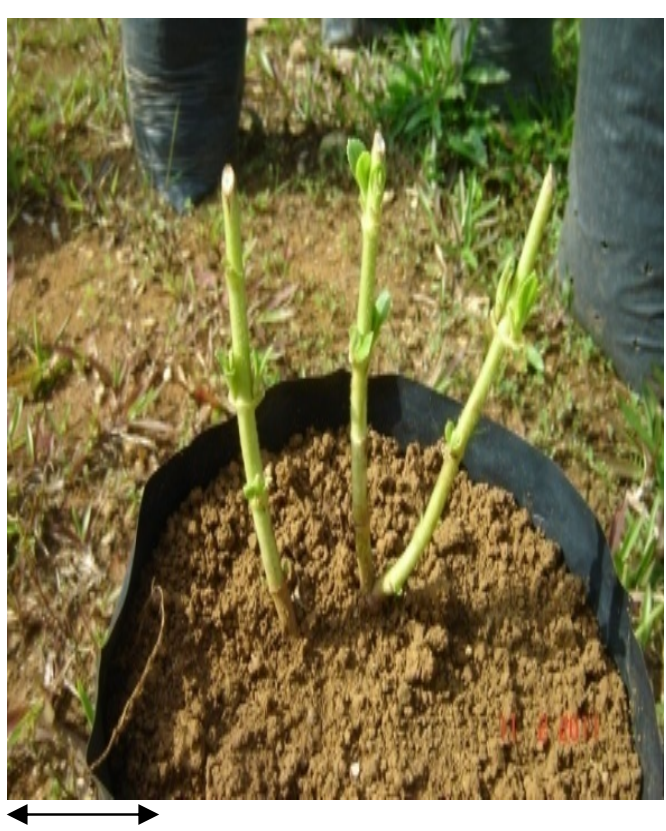

$1 \mathrm{~cm}$

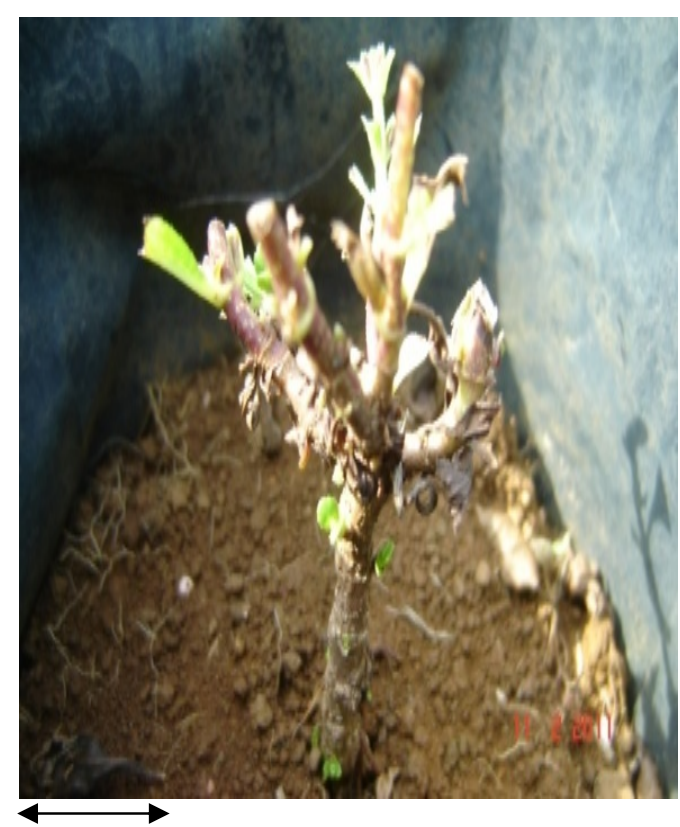

$1 \mathrm{~cm}$

Figure 4a

figure $4 b$

Figures $4 a-4 b$. Showed some pruned Stevia plants 


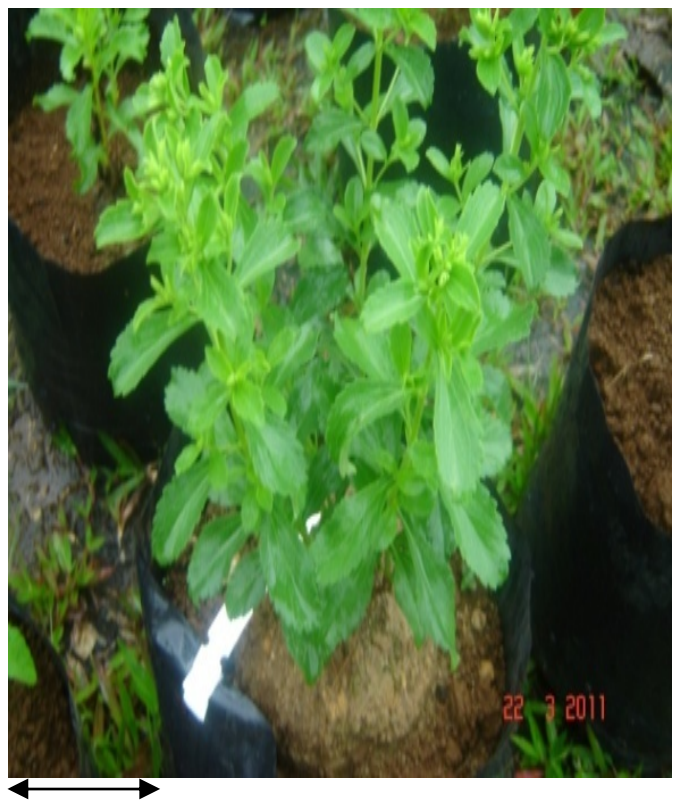

$1 \mathrm{~cm}$

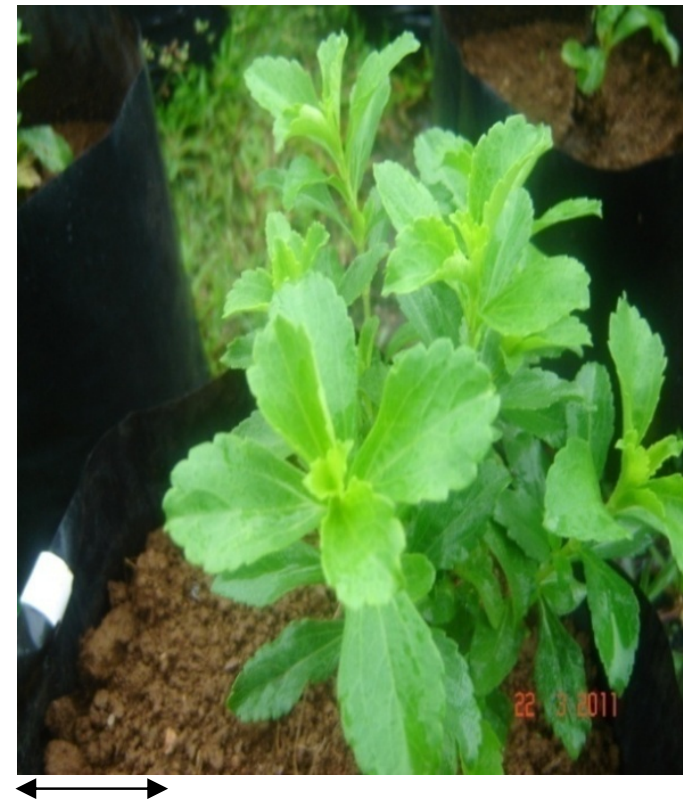

$1 \mathrm{~cm}$

Figure 5a

figure $5 b$

Figures $5 \mathrm{a}-5 \mathrm{~b}$. Showed some growing Stevia plants after pruning treatment 